\title{
Transcription of Cytokeratins 8, 18, and 19 in Bone Marrow and Limited Expression of Cytokeratins 7 and 20 by Carcinoma Cells: Inherent Limitations for RT-PCR in the Detection of Isolated Tumor Cells
}

\author{
Arno Dimmler, Roswitha Gerhards, Christoph Betz, Klaus Günther, \\ Bertram Reingruber, Thomas Horbach, Irith Baumann, Thomas Kirchner, \\ Werner Hohenberger, and Thomas Papadopoulos
}

Institute of Pathology (AD, CB, IB, TK, TP) and Department of Surgery (KG, BR, TH, WH), University of Erlangen-Nürnberg, Erlangen; and Department of Oncology (RG), Marienhospital-Herne, Ruhr University Bochum, Bochum, Germany

SUMMARY: The suitability of "real-time" quantitative reverse transcriptase polymerase chain reaction (RT-PCR) for the detection of isolated carcinoma cells in bone marrow was investigated by evaluating the expression of cytokeratin (CK)7, CK8, CK18, CK19, and CK20 in 17 gastrointestinal cancer cell lines, 64 control bone marrow specimens from noncancer patients, and 30 bone marrow specimens from patients with gastric or colorectal cancer. RT-PCR products for CK8 and CK18 were detected in all cancer cell lines, but only 16, 5, and 11 cell lines provided evidence for CK19, CK7, and CK20 transcription. Variable numbers of bone marrow specimens from noncancer patients demonstrated background transcription of CK8 (78.1\%), CK18 (95.3\%), CK19 (35.9\%), CK20 (29.6\%), and CK7 (16.7\%). Maximal background transcription for CK8, CK18, and CK19 ranged from 52.2 to 56.1 copies $/ 10^{3}$ copies glyceraldehyde-3-phosphate dehydrogenase (GAPDH), the corresponding values of 0.06 and 0.76 copies for CK7 and CK20 being distinctly lower. When maximal background values were used as a threshold value to define positivity in tumor cell dilution experiments, sensitivity levels of one tumor cell in $10^{4}$ bone marrow cells were determined for CK7 and CK20 RT-PCR assays. Maximal background expression values of the different CKs as obtained in the control series were exceeded once (CK20), twice (CK18 and CK19), and 18 times (CK7) in bone marrow specimens from cancer patients, with none of these specimens exceeding the maximal background expression value of CK8. We conclude that RT-PCR for CK8, CK18, and CK19 cannot be recommended for the detection of isolated tumor cells in bone marrow of cancer patients. On the other side, the limited number of gastric and colorectal cancer cell lines expressing CK7 and CK20 indicates that assay sensitivity for these CKs might be limited because of their selective expression by carcinoma cells. (Lab Invest 2001, 81:1351-1361).

$T$ he utility of reverse transcriptase polymerase chain reaction (RT-PCR) assays designed for the detection of isolated tumor cells by the use of tissue specific primers, eg, cytokeratins (CKs), is controversially discussed. High sensitivity has been claimed to be one of the major advantages of RT-PCR when compared with immunocytological techniques (Deguchi et al, 1993; Noguchi et al, 1994; Smith et al, 2000). In cancer cell dilution experiments, RT-PCR assays with primers for CKs, prostata-specific antigen, and surfactant proteins have been capable of detecting up to one cancer cell in $10^{7}$ normal cells (Betz et al, 1995; Ghossein et al, 1995). This sensitivity level is 10- to 100-fold higher than that of comparable immunocytological assays. Technical feasibility and cost effective-

Received April 3, 2001.

This research was supported by Johannes und Frieda Marohn Stiftung, University of Erlangen-Nürnberg.

Address reprint requests to: Prof. Dr. Thomas Papadopoulos, Institute of Pathology, University of Erlangen-Nürnberg, Krankenhausstr. 8-10, 91054 Erlangen, Germany.E-mail: thomas.papadopoulos@patho.imed.uni-erlangen.de ness of the RT-PCR technique are other arguments for introducing this technique as a clinically relevant methodology for the detection of isolated tumor cells in common epithelial cancers (Lockett et al, 1998).

On the other side, inherent methodological problems of RT-PCR with tissue-specific primers are still unresolved. In contrast to RT-PCR assays based on the amplification of tumor-specific mRNA sequences as used in the molecular diagnosis of leukemias and sarcomas (Athale et al, 2001; Fischmeister et al, 1999; Hochhaus et al, 2000; van Dongen et al, 1999), falsepositive results in RT-PCR assays with tissue-specific primers may be caused by the coamplification of pseudogenes (Ruud et al, 1999; Savtchenko et al, 1988) but also by illegitimate background transcription of the target genes by the nonneoplastic cells of the sample. Amplification of pseudogenes often results from contamination of the mRNA probes by traces of genomic DNA and can be identified by control experiments in which parallel samples are processed without reverse transcription (Dingemans et al, 1997). It can be avoided by choosing intron-overlapping primer 
sets and/or by DNAse treatment of the mRNA probe before reverse transcription proceeds. Illegitimate background transcription poses a much more serious methodological disadvantage than pseudogenes. The phenomenon was firstly identified by Chelly and colleagues (1989) and has so far been described for almost all of the candidate tissue-specific target genes, including CK8 (Traweek et al, 1993), CK18 (Traweek et al, 1993), CK19 (Dingemans et al, 1997), prostata-specific antigen (Mclntyre et al, 2000; Smith et al, 1995), and surfactant protein B (Betz et al, 1995). Only a few quantitative evaluations of illegitimate transcription in bone marrow have been performed so far (Salbe et al, 2000; Slade et al, 1999). Like previously performed semiquantitative evaluations, they report on rather unstable levels of background transcription for each target gene and primer set. For some of these target genes, like CK19 and carcinoembryonic antigen (CEA), inflammation and cytokines have been shown to up-regulate background transcription in bone marrow (Jung et al, 1998). This variability further exaggerates the problem of discrimination between amplification products obtained from tumor cells and false-positive results obtained from background transcription.

Because background transcription for most of the target genes is unavoidable, quantification of the amplification product and subsequent definition of cut-off points for each target gene is the only way to improve specificity of tissue-specific RT-PCR assays. In the present study, we have addressed this problem by developing quantitative RT-PCR assays for all CKs that are expressed by adenocarcinomas. The quantitative assays were performed using the fluorometric "real-time" quantitative RT-PCR technique and the
TaqMan technology. Levels of illegitimate transcription were evaluated in 64 control bone marrow specimens and cut-off points were defined for each CK separately. The sensitivity of the technique was evaluated by comparing the cut-off points obtained in the control series with values obtained in dilution experiments with CK-positive cancer cell lines. Subsequent evaluation of CK gene expression in immunocytologically positive bone marrow specimens from patients with gastrointestinal cancer clearly demonstrates that variable background transcription of CK mRNA by nonneoplastic bone marrow cells and differential CK expression by carcinoma cells are both important limiting factors for the use of the CK RT-PCR assay in the detection of isolated tumor cells.

\section{Results}

\section{CK Expression in Gastrointestinal Cancer Cell Lines}

The quantitative expression values obtained for the different CKs are listed in Table 1. Expression of CK8, CK18, and CK19 was demonstrated in nearly all cell lines. Colo320 was the only cell line with almost no CK expression. With one exception CK18 expression values were always higher than the corresponding values for CK8 or CK19. Only in cultures of the Colo201 cell line were expression values for CK19 shown to be higher than for CK18.

CK7 and CK20 were expressed in a nearly complementary manner by gastric and colorectal cancer cell lines. Expression of CK7 was mainly restricted to the three gastric cancer cell lines. Only two of the colorectal cell lines demonstrated low levels of CK7 expression $\left(<15\right.$ copies $/ 10^{3}$ copies glyceraldehyde-3-

Table 1. Cytokeratin Transcription in Gastric and Colorectal Cancer Cell Lines

\begin{tabular}{|c|c|c|c|c|c|c|}
\hline \multirow[b]{2}{*}{ Cell line } & \multirow[b]{2}{*}{ ATCC No. } & \multicolumn{5}{|c|}{ Cytokeratin (molecules per 1000 molecules GAPDH) ${ }^{a}$} \\
\hline & & 7 & 8 & 18 & 19 & 20 \\
\hline $23132 / 87^{b}$ & - & $89 \pm 88$ & $146 \pm 49$ & $1000 \pm 679$ & $180 \pm 96$ & $823 \pm 427$ \\
\hline MKN45 & - & $264 \pm 164$ & $22 \pm 14$ & $1963 \pm 934$ & $189 \pm 106$ & 0 \\
\hline KatollI $^{b}$ & HTB-103 & $1989 \pm 1309$ & $127 \pm 53$ & $1794 \pm 633$ & $146 \pm 78$ & 0 \\
\hline $\mathrm{CaCo}^{c}$ & HTB-37 & $6 \pm 6$ & $88 \pm 47$ & $661 \pm 377$ & $186 \pm 149$ & $69 \pm 47$ \\
\hline Colo201 ${ }^{c}$ & CCL-224 & 0 & $99 \pm 25$ & $871 \pm 254$ & $1548 \pm 997$ & $94 \pm 49$ \\
\hline Colo320 & CCL-220 & 0 & $2 \pm 1$ & $51 \pm 28$ & 0 & $9 \pm 5$ \\
\hline HCT116 $^{c}$ & CCL-247 & $14 \pm 7$ & $35 \pm 12$ & $647 \pm 295$ & $278 \pm 138$ & $11 \pm 7$ \\
\hline HCT15 ${ }^{c}$ & CCL-225 & 0 & $124 \pm 98$ & $462 \pm 225$ & $98 \pm 54$ & 0 \\
\hline $\mathrm{HCT}^{c}{ }^{c}$ & CCL-244 & 0 & $162 \pm 129$ & $898 \pm 622$ & $222 \pm 175$ & $28 \pm 17$ \\
\hline $\mathrm{HT} 2 \mathrm{~g}^{c}$ & HTB-38 & 0 & $351 \pm 298$ & $1123 \pm 570$ & $246 \pm 145$ & $2749 \pm 1800$ \\
\hline $\mathrm{LoVO}^{c}$ & CCL-229 & 0 & $96 \pm 15$ & $1090 \pm 768$ & $99 \pm 86$ & $5 \pm 3$ \\
\hline SW $1116^{c}$ & CCL-233 & 0 & $122 \pm 42$ & $947 \pm 304$ & $275 \pm 146$ & $811 \pm 432$ \\
\hline SW $403^{c}$ & CCL-230 & 0 & $43 \pm 24$ & $490 \pm 105$ & $100 \pm 53$ & $142 \pm 85$ \\
\hline SW $480^{\circ}$ & CCL-228 & 0 & $61 \pm 32$ & $650 \pm 330$ & $135 \pm 71$ & 0 \\
\hline SW620 & CCL-227 & 0 & $52 \pm 19$ & $972 \pm 339$ & $116 \pm 50$ & 0 \\
\hline SW948 ${ }^{c}$ & CCL-237 & 0 & $87 \pm 47$ & $856 \pm 351$ & $166 \pm 122$ & $485 \pm 154$ \\
\hline WIDR $^{c}$ & CCL-218 & 0 & $87 \pm 3$ & $669 \pm 135$ & $39 \pm 21$ & $489 \pm 380$ \\
\hline
\end{tabular}

GAPDH, glyceraldehyde-3-phosphate dehydrogenase; ATCC, American Type Culture Collection.

${ }^{a}$ Data are means \pm standard error of the mean of values obtained from 4 separate cultures.

${ }^{b}$ Gastric cancer cell line.

${ }^{c}$ Colonic cancer cell line. 
phosphate dehydrogenase [GAPDH]) in addition to the expression of CK20. CK20 was detected in 11 of 14 colorectal cancer cell lines; only one gastric cell line demonstrated an additional expression of CK2O besides the expression of CK7. In 3 of 11 CK20-positive colorectal cancer cell lines, expression levels for CK20 were very low, not exceeding a mean value of 15 copies $/ 10^{3}$ copies GAPDH.

\section{Background Transcription in Bone Marrow Aspirates from Noncancer Patients}

Background transcription of CK8, CK18, and CK19 was detected in 78.1\% $(n=50 / 64), 95.3 \%(n=$ $61 / 64)$, and $35.9 \%(n=23 / 64)$ of the noncancer bone marrow specimens, respectively. Levels of expression were highly variable (Fig. 1A). Mean values of background transcription were shown to be rather high for CK18 (6.42 copies $/ 10^{3}$ copies GAPDH) and lower for CK8 (4.96 copies $/ 10^{3}$ copies GAPDH) and CK19 (3.21 copies $/ 10^{3}$ copies GAPDH). In contrast, maximal background expression levels for all three CKs were nearly the same; the maximal values ranged between 56.1 and 52.2 copies $/ 10^{3}$ copies GAPDH.

In most aspirates no background expression was obtained for CK7 and CK20. Only 9 of 54 specimens (16.7\%) demonstrated minimal expression of CK7, with a mean expression value of 0.03 copies $/ 10^{3}$ copies GAPDH (Fig. 1B). Slightly higher expression levels were also obtained in 16 of 54 control specimens (29.7\%) for CK20, with mean expression levels of 0.18 copies $/ 10^{3}$ copies GAPDH (Fig. 1B).

\section{Sensitivity Assays with MKN45 and HT29 Cells}

When CK background transcription of individual bone marrow samples was used to define the sensitivity of the CK8, CK18, and CK19 RT-PCR assays, sensitivity levels of up to one tumor cell in $10^{7}$ bone marrow cells were evaluated (Fig. 2). However, when base lines of background transcription were defined by the maximal value obtained from the whole series of control bone marrows, no carcinoma cells were detectable by CK8, CK18, and CK19 expression, even at a minimal dilution of one tumor cell in $10^{3}$ bone marrow cells (Fig. 2).

No background expression of CK7 and CK20 mRNA was measurable in both bone marrow specimens with which the tumor cell dilutions of MKN45 and HT29 cells were performed (Fig. 2). mRNA of CK7 was detected by RT-PCR at a tumor cell density as low as one MKN45 cell in $10^{5}$ bone marrow cells. A similar tumor cell density of one HT29 cell in $10^{5}$ bone marrow cells was detectable by the RT-PCR assay for CK20. When maximal background transcription levels of the control bone marrow series (compare Fig. 1) were used as a threshold to define positivity of the CK7 and CK20 RT-PCR assays, only sensitivity levels of one tumor cell in $10^{4}$ bone marrow cells were evaluated for both assays.

\section{Detection of Carcinoma Cells by CK RT-PCR in Bone Marrow Aspirates from Patients with Gastric or Colorectal Cancer}

The CK-positivity rate of bone marrow specimens from patients with colonic and gastric carcinoma was extremely low when maximal background transcription levels of CKs were used as a threshold to discriminate background transcription from tissue-specific CK expression by carcinoma cells. In none of the samples from cancer patients were transcription levels of CK8 higher than the maximal level of background
A

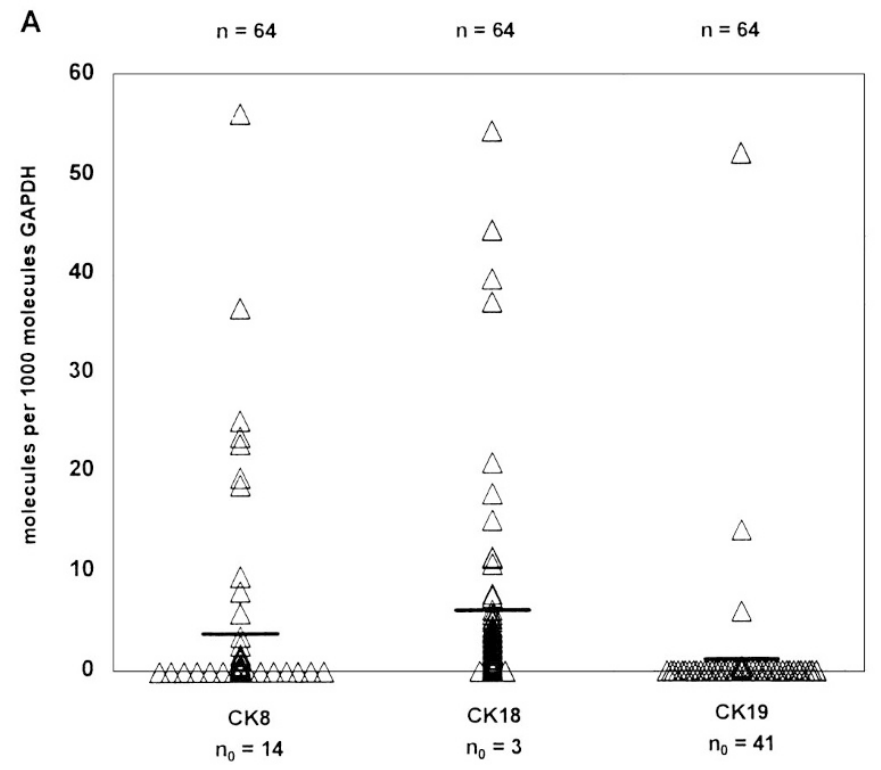

B
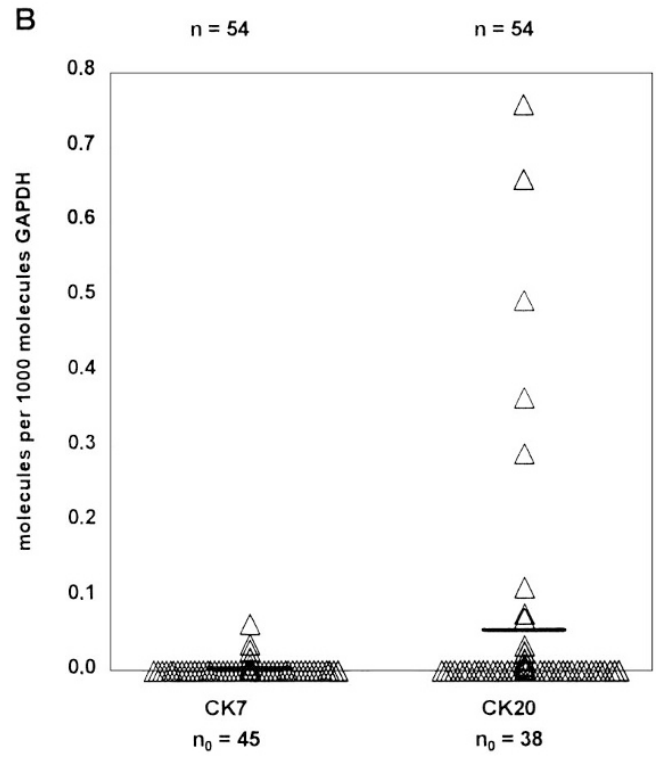

Figure 1.

Background transcription of cytokeratin (CK)8, CK18, CK19, CK7, and CK20 in bone marrow aspirates from noncancer patients. Each triangle represents the value obtained from a single aspirate. For each type of CK, mean values (bars), the total number of aspirates analyzed $(n)$, and the number of aspirates without detectable CK transcription $\left(n_{0}\right)$ are indicated. GAPDH, glyceraldehyde-3-phosphate dehydrogenase. 


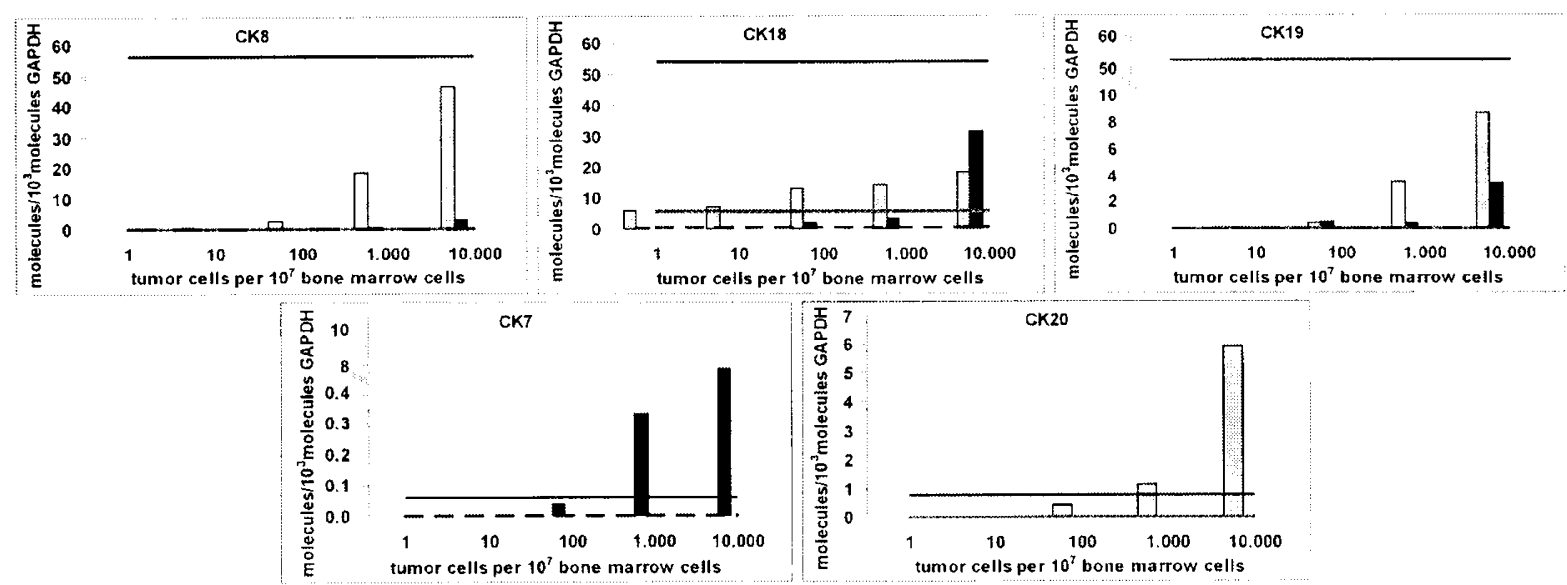

Figure 2.

Sensitivity of the real-time quantitative reverse transcriptase polymerase chain reaction (RT-PCR) for the different CKs was tested by preparing serial dilutions of the cancer cell lines MKN45 (CK8+, CK18+, CK19+, CK7+; black bars) and HT29 (CK8+, CK18+, CK19+, CK20+; gray bars) in bone marrow aspirates from patients without epithelial cancer. Each cell line was seeded in one bone marrow aspirate of a single patient. Each bar is the mean value of three measurements. The solid gray line and the interrupted black line indicate CK background transcription of the two individual bone marrow specimens with which the dilutions were performed. The solid black line indicates maximal CK background transcription as it was evaluated in the control experiment performed with a total of 64 aspirates from noncancer patients (compare also Fig. 1).

transcription obtained in the control series (Fig. 3). From the 30 samples that were analyzed in the same manner for CK18 and CK19, two samples were always positive for each of these CKs (Fig. 3). Only one further sample provided a distinct positivity for CK20 (Fig. 4). On the other hand, a high positivity rate was evaluated for CK7, with $60 \%$ of the cases $(n=18)$ providing higher CK7 transcription values than the corresponding maximal background transcription level obtained in the control series (Fig. 4). Even when the cut-off level for CK7 was arbitrarily defined as a value twice as high as the maximal background transcription level, positivity was still detectable in $50 \%$ of the cases $(n=$ 15/30).

\section{Comparison of Immunocytology and Quantitative RT-PCR}

The positivity rate in bone marrow aspirates from patients with gastrointestinal cancer was distinctly higher when immunocytology was applied instead of quantitative RT-PCR for CK8, CK18, and CK19. Fifteen of the 30 aspirates were positive by the use of the anticytokeratin monoclonal antibody A45-B/B3 (Conrad et al, 1988; Stigbrand et al, 1998), but only three samples of the same series were proven to be positive with CK8, CK18, and CK19 RT-PCR (Fig. 3). Only two of these three specimens were shown to be positive by the use of both methodologies.

Besides its proven reactivity for CK8-18 and CK8-19 (Stigbrand et al, 1998), A45-B/B3 is also supposed to react with CK7 (Conrad et al, 1988). Comparing A45-B/B3-positivity with the data obtained by CK7 RT-PCR (Fig. 4), 10 of the 18 CK7 mRNApositive specimens were also proven to be positive by the use of immunocytology.

\section{Discussion}

CKs are the most reliable markers of epithelial differentiation and have therefore been widely applied to identify the epithelial differentiation of neoplastic cells (Moll, 1993; Moll et al, 1982). For the same reason most of the immunocytological studies dealing with the detection and prognostic significance of occult tumor cell dissemination in common epithelial cancers have been performed with monoclonal antibodies specific for CKs (Braun et al, 2000; Heiss et al, 1995; Pantel et al, 1996). In these studies, single CK-positive cells were also infrequently detected in control bone marrow specimens from noncancer patients; the percentage of such false-positive specimens in the large control series from noncancer patients ranged between 1\% (Pantel et al, 1996) and 2.8\% (Braun et al, 2000). This low frequency of CK-positive control bone marrows did not pose a serious problem for the specificity of the tumor cell detection assays and has so far gained only little attention by the investigators. Explanations that have been proposed by some investigators for such a false positivity include false crossreactivity of the antibodies applied and false positivity caused by incomplete blocking of the endogenous alkaline phosphatase activity, especially when the alkaline phosphatase, antialkaline phosphatase staining technique was applied to visualize the positive cells (Borgen et al, 1998).

In contrast to the infrequent detection of CKpositive bone marrow cells by immunocytochemistry, background transcription, at least for the common "primitive" CK8, CK18, and CK19, has rather commonly been detected in bone marrow specimens from noncancer patients (Traweek et al, 1993). Positivity values of up to $100 \%$ have so far been reported for CK8 and CK18. This rather high frequency poses a major problem for RT-PCR assays designed to identify carcinoma cells in bone marrow specimens.

The aim of the present study was to evaluate the suitability of a quantitative RT-PCR approach in such a way that discrimination between $\mathrm{CK}$ background transcription by the bone marrow cells and tissue- 

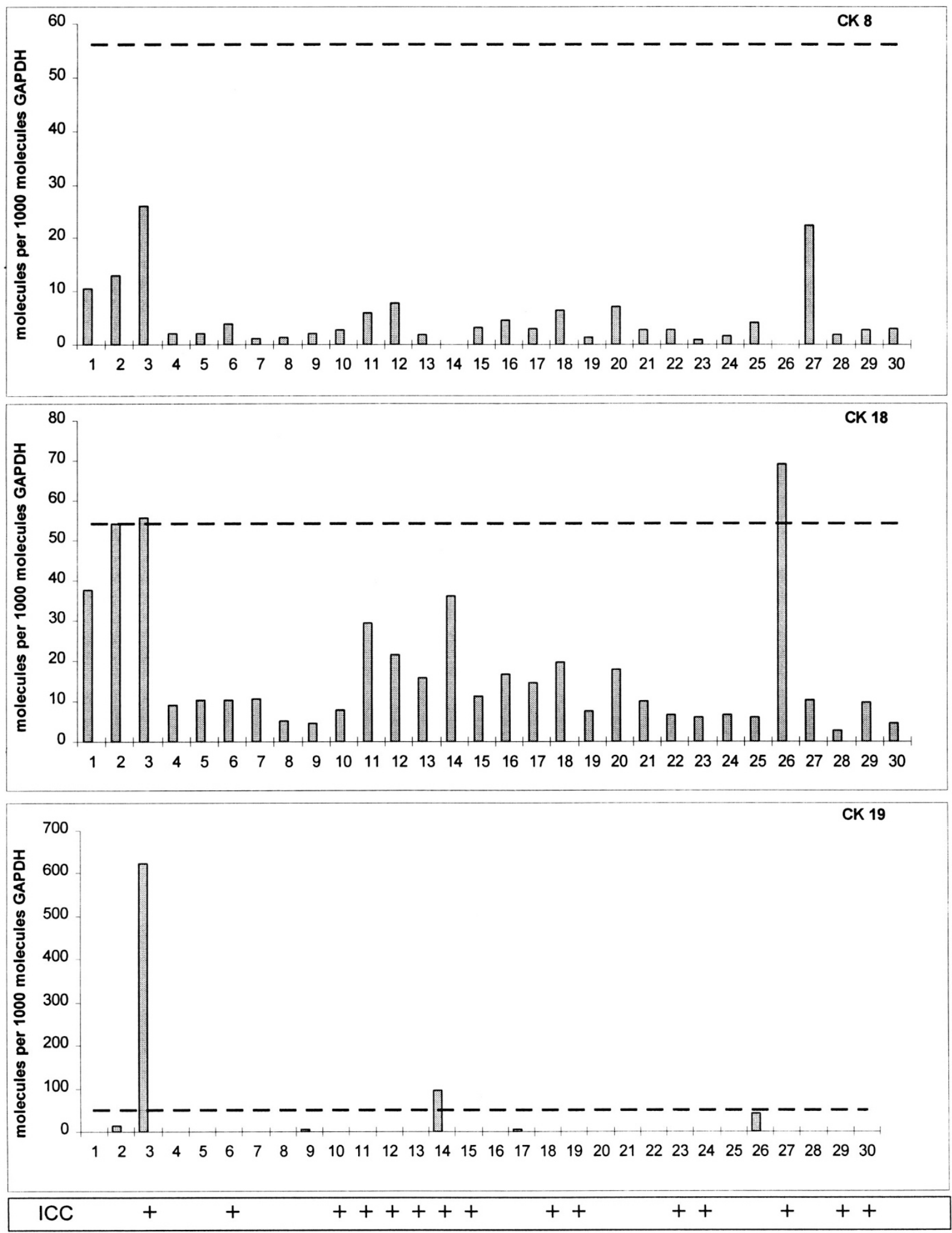

Figure 3.

Transcription of CK8, CK18, and CK19 in bone marrow aspirates from patients with gastric (Nos. 1-9) and colorectal (Nos. 10-30) cancer. Each bar represents the value of a single bone marrow aspirate and is the mean of three measurements. The interrupted black line indicates maximal background transcription as it was evaluated in the control experiment with bone marrow aspirates from noncancer patients (compare also Fig. 1). +, Indicates bone marrow specimens with A45-B/B3-positive cells as detected by the use of immunocytochemistry (ICC). 

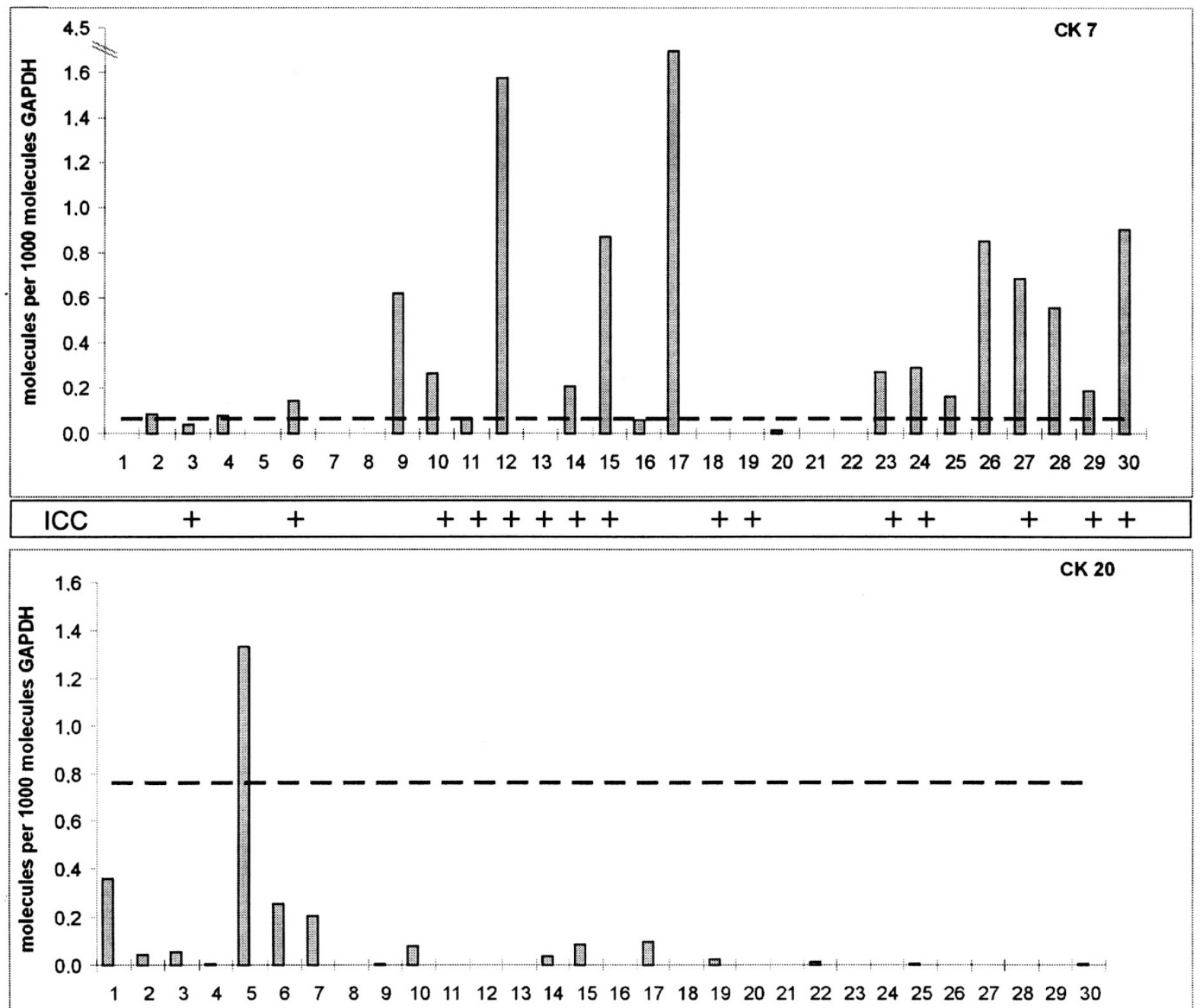

Figure 4.

Transcription of CK7 and CK20 in bone marrow aspirates from patients with gastric (Nos. 1-9) and colorectal (Nos. 10-30) cancer. Each bar represents the value of a single bone marrow aspirate and is the mean of three measurements. The interrupted black line indicates maximal background transcription as it was evaluated in the control experiment with bone marrow aspirates from noncancer patients (compare also Fig. 1). +, Indicates bone marrow specimens with A45-B/B3-positive cells as detected by the use of immunocytochemistry.

specific CK expression by disseminated carcinoma cells would become possible. Adequate sensitivity of such an assay is a decisive prerequisite for its clinical validity and requires a minimum difference in expression levels of the target transcript in the tumor cells compared with the surrounding normal tissue. To address this problem we have developed a quantitative RT-PCR assay by using the fluorometric real-time PCR technique, the TaqMan technology, and primer pairs specific for a panel of CKs that are all differentially expressed by adenocarcinomas.

Because pseudogene coamplification was previously identified to be a major source of false positivity in RT-PCR assays (Dingemans et al, 1997), the experimental design of the present analysis was modified in such a manner that coamplification of pseudogenes could largely be excluded. In a preliminary experiment with control bone marrow specimens from noncancer patients, we have shown that significant coamplification of CK8, CK18, and CK19 pseudogenes was unavoidable if mRNA probes were not pretreated with DNAse before being further processed by reverse transcriptase (data not shown). Consequently, all mRNA sample aliquots in the main experiment that were used for CK8, CK18, and CK19 RT-PCR assays were treated with DNAse, thus avoiding contamination of the cDNA samples by genomic DNA from pseudogenes. On the other hand, no DNAse treatment was necessary for samples processed for CK7 and CK20 RT-PCR assays. Besides the fact that no CK7 or CK20 pseudogenes have been described so far (compare GenBank sequence database), the number of the amplicons obtained in the control experiments by amplification of mRNA aliquots without reverse transcription has always been negligible, because it never accounted for more than $5 \%$ of the total amplification product after reverse transcription. In our opinion, this minimal observed amplification of genomic DNA using intron-spanning primers for CK7 and CK20 is not necessarily indicative for the existence of CK7 and/or 
CK20 pseudogenes and could also be interpreted as a result of the known reverse transcriptase-activity of the Taq-polymerase (Tse and Forget, 1990).

Because incidental coamplification of pseudogenes was largely excluded by the experimental procedure we have chosen, amplification of CK transcripts in the control series from noncancer patients was always interpreted as "illegitimate" background transcription. In accordance with previous investigations by Traweek et al (1993), background transcription of CK8 and CK18 was very often detected in control bone marrow specimens. Levels of expression in the individual specimens demonstrated high variability, with mean values of CK8 and CK18 expression sometimes being as high as the corresponding transcription levels of CK8 and CK18 in carcinoma cell lines with low or even intermediate CK expression levels. So far, it is not surprising that cut-off levels based on the maximal background expression levels of CK8 and CK18 in the control series obviously preclude detection of carcinoma cells in the dilution assays, even in specimens with the highest tumor load of one MKN45 cell in $10^{3}$ bone marrow cells. Likewise, in accordance with the data obtained in the dilution experiments, none of the bone marrow specimens from patients with gastric or colonic carcinoma demonstrated levels of CK8 expression higher than the level of maximal background expression in the control series. With respect to CK18, only 2 of 30 bone marrow specimens yielded values higher than the threshold value, as defined by the maximal level of CK18 background transcription. In the same series of bone marrow specimens from cancer patients, immunocytological examination using the pan-cytokeratin antibody A45-B/B3 (Stigbrand et al, 1998) revealed CK-positive cells in 15 of 30 cases, thus indicating that CK immunocytology might be more suitable for the detection of CK-positive cells than quantitative RT-PCR.

Several investigators have used CK19 transcripts as a tissue-specific marker for the detection of metastatic epithelial cancer in lymph nodes (Van Trappen et al, 2001), bone marrow (Datta et al, 1994; Krüger et al, 1996), and blood specimens (Datta et al, 1994; Dingemans et al, 1997). However, the variable positivity rates in a series of control specimens obtained by different investigators have led to a controversial discussion regarding the suitability of this marker for the detection of isolated cancer cells. In a control series of bone marrow specimens analyzed by Traweek et al (1993), no transcription of CK19 was observed in all 7 specimens. Low positivity rates, with 1 positive specimen in a series of 29 , were observed by Datta et al (1994), and 2 positive specimens were evaluated in a series of 52 cases by Moscinski et al (1996). Higher positivity rates in the control series were obtained by Slade et al (1999) ( $n=12 / 30)$ and Jung et al (1998) ( $n$ $=8 / 31)$. In the present series, which to our knowledge is the largest series from noncancer patients examined by RT-PCR assays so far, false positivity was detected in 23 out of 64 cases (35.9\%), the results being comparable to the data of Slade et al (1999) and Jung et al (1998). The levels for CK19 transcription in the present series ranged from 0.002 copies $/ 10^{3}$ copies GAPDH to maximal levels of 52.18 copies $/ 10^{3}$ copies GAPDH; the mean values of CK19 background transcription were distinctly lower than the corresponding levels for CK8 and CK18. When maximal background transcription levels were used as a threshold level to discriminate background transcription from tissue-specific transcription by carcinoma cells, only three specimens from patients with gastric or colonic cancer provided values indicative of an "occult" carcinoma cell dissemination in the bone marrow. Finally, in the dilution experiments with MKN45 and HT29 cells, even the highest tumor cell density of one carcinoma cell in $10^{3}$ bone marrow cells provided CK19 transcription levels lower than the threshold level, which was defined as the maximal level obtained in the control series. So far, the data in the present investigation do not encourage the application of a CK19 RT-PCR for the analysis of disseminated carcinoma cells in bone marrow.

In contrast to the results obtained for CK8, CK18, and CK19, illegitimate transcription of CK7 and CK20 by bone marrow cells does not seem to be a major problem for the detection of isolated tumor cells in the present series. Only 9 of 54 control bone marrow samples from patients without cancer demonstrated a background transcription for CK7. These levels were very low and never exceeded a maximal value of about 0.062 , which is nearly $10^{4}$ times as low as the corresponding maximal background expression levels for CK8, CK18, and CK19. The corresponding maximal background expression level for CK20 was also nearly $10^{3}$ times as low as the maximal CK8, CK18, and CK19 values; only 16 of 54 control bone marrow specimens demonstrated a CK20 background transcription at all.

However, even these low background expression levels have led to a decreased sensitivity of the RT-PCR assays in the dilution experiment. Only densities of up to one tumor cell in $10^{4}$ bone marrow cells remained detectable when threshold levels were defined by the maximal levels of background transcription.

Also surprisingly low was the CK20-positivity rate among the bone marrow specimens from 9 gastric and 21 colonic cancer patients. This finding is surprising because most of the human colonic carcinomas and at least some of the gastric carcinomas are supposed to be CK20-positive, at least by the use of immunohistochemistry (Moll et al, 1993). On the other side, only 9 of 14 colorectal cancer cell lines (64\%) and only 1 of 3 gastric cell lines (33\%) demonstrated CK20 transcription levels of more than 10 copies per $10^{3}$ copies GAPDH by the use of RT-PCR. The reason for the discrepancy between the known high immunohistochemical CK20-positivity rate of primary colorectal cancers and the low positivity rate for CK20 mRNA in disseminated carcinoma cells and cancer cell lines is unclear and requires further investigation. One possible mechanism that might explain this disparity is the down-regulation of CK20 mRNA expression in disseminated carcinoma cells when compared with the 
expression of CK20 within the primary tumor. An alternative explanation could be a differential and disparate expression of CK20 mRNA and protein within the carcinoma cells, as has already been described for CK14 in prostatic epithelia (Yang et al, 1997). To our knowledge, no studies concerning posttranscriptional regulation and half-lives of CK20 mRNA and protein exist so far. The data from the present investigation seem to suggest, however, that the low detection rate of carcinoma cells by CK20 RT-PCR is more a result of a selective and differential expression of CK20 by carcinoma cells and, only to a lesser degree, a result of insufficient discrimination caused by elevated CK20 background expression by bone marrow cells. Candidate cells for such a background expression are the neutrophil granulocytes that have previously been demonstrated to express CK20, at least at the level of mRNA (Jung et al, 1999).

The highest positivity rates in the series of bone marrow specimens from patients with gastrointestinal cancer were obtained by the use of the CK7 RT-PCR. Eighteen of 30 patients demonstrated CK7 transcription levels higher than the maximal level of background transcription. This is obviously due to the very low background transcription levels of CK7, which have been the lowest among the CKs tested in this series. However, similar to CK20, CK7 is also selectively expressed by carcinoma cells; ie, immunohistochemically CK7 is only sometimes detectable in gastric cancer (Chu et al, 2000) and rather seldom in colorectal carcinomas (Berezowski et al, 1996; Lagendijk et al, 1999; Loy and Calaluce, 1994; Loy et al, 1996). So far, the CK7-positivity rate in 13 of 21 bone marrow specimens from patients with colorectal cancer in the present series seems to be unexpectedly high. Whether this high positivity rate at the mRNA level also reflects CK7-positivity of the disseminated cells at the protein level cannot be answered with certainty because of the broad spectrum reactivity of the antibody applied (Conrad et al, 1988; Stigbrand et al, 1998). Nevertheless, with 10 of 18 of the immunocytologically positive cases also demonstrating a CK7 mRNA-positivity, it seems to be at least a partial correlation of the CK7 mRNA-positivity and the immunocytological results. Based on the known CKreactivity pattern of $A 45-B / B 3$, which may also react with CK7 (Conrad et al, 1988), and considering the finding of an almost completely missing mRNApositivity for CK8, CK18, and CK19 in the same series, one could speculate that the immunocytological CKpositivity obtained in the present investigation might partially depend on the CK7-positivity of the tumor cells. Further investigations with antibodies that specifically react with $\mathrm{CK} 7$ are required to confirm or exclude a CK7-positivity of disseminated tumor cells from patients with colorectal cancer at the protein level. Finally, sampling errors or, alternatively, an unbalanced expression of CK7 mRNA and protein could be two different explanations for the missing immunocytological positivity in eight CK7 mRNA-positive marrow specimens in this series.
In summary, the data presented here suggest that high and variable levels of CK8, CK18, and CK19 illegitimate transcription by bone marrow cells obviously preclude detection of isolated carcinoma cells in the bone marrow by the use of CK8, CK18, and CK19 RT-PCR assays. In contrast, rather low levels of CK7 and CK20 background transcription may have an influence on the sensitivity of the RT-PCR assays but do not principally exclude CK7 and CK20 RT-PCR assays as a detection method for isolated carcinoma cells. The restricted expression of CK7 and CK20 by carcinoma cells has an additional adverse effect on the sensitivity of the CK7 and CK20 assays, which, however, might be partially overcome by the use of multiplex RT-PCR assays with primers for both CKs and, perhaps, also other molecular markers with low levels of illegitimate background transcription.

\section{Materials and Methods}

\section{Cell Lines}

Three gastric and 14 colorectal cancer cell lines were included in this study (Table 1). They were all provided by the American Type Culture Collection (Rockville, Maryland), except 23132/87 (Vollmers et al, 1993) and MKN45 (Naito et al, 1984), which were purchased from the Deutsche Sammlung von Mikroorganismen und Zellkulturen GmbH (Braunschweig, Germany).

\section{Bone Marrow Aspirates}

After giving informed consent, 9 patients with gastric and 21 patients with colorectal adenocarcinoma were recruited for this study. They underwent bone marrow aspiration from the posterior iliacal crest before the removal of the primary carcinoma. Specimens from 64 patients, who underwent bone marrow aspiration because of a nonneoplastic hematologic or inflammatory disease, were used as a control series for the evaluation of CK background transcription. None of the control patients had evidence of epithelial cancer. The volume of all aspirates ranged from 3 to $15 \mathrm{ml}$ (mean, $5 \mathrm{ml}$ ). The cell suspension was diluted in 2 volumes of PBS. Mononuclear cells were isolated by density centrifugation through Ficoll-Hypaque (Biochrom, Berlin, Germany). The interphase cell fraction was collected and washed twice in PBS. The mononuclear cells were counted and aliquoted for immunocytochemistry, quantitative RT-PCR for CK8, CK18, and CK19 (RNA isolation combined with DNAse treatment), and quantitative RT-PCR for CK7 and CK20 (RNA isolation without DNAse treatment) on the basis of at least $2 \times 10^{6}$ cells for each methodology. Aliquots for immunocytochemistry were obtained only from the aspirate series of cancer patients and not from the specimens of the control series.

\section{Immunocytochemistry}

The monoclonal antibody A45-B/B3 (Epimet Kit; Baxter, Unterschleißheim, Germany), which is directed against a common epitope of cytokeratin polypep- 
tides, including the cytokeratin hetertodimers 8-18 and 8-19 (Stigbrand et al, 1998) and CK7 (Conrad et al, 1988), was used to detect carcinoma cells in bone marrow cytospin preparations. After cytocentrifugation, cells were air-dried and fixed for 10 minutes with acetone at $-20^{\circ} \mathrm{C}$. Visualization of the antibody reaction was performed using the indirect alkaline phosphatase technique. No counterstain was performed. HT29 cells served as a positive control. An appropriate dilution of a monoclonal antibody with irrelevant specificity (anti-FITC) served as an IgG isotype control. For each bone marrow specimen, $2 \times 10^{6}$ cells were screened by bright-field microscopy.

\section{RNA Isolation and Reverse Transcription}

Total cellular RNA was extracted from the cell lysates by the RNeasy Kit (Qiagen, Hilden, Germany), as described in the manual. Aliquots that were subsequently processed for the evaluation of CK8, CK18, and CK19 transcription always underwent treatment with DNAse (RNeasy kit). In contrast, no DNAse treatment was performed with aliquots used for the evaluation of CK7 and CK20 transcription. The RNA was eluted in $30 \mu \mathrm{l}$ of RNAse-free water. First-strand cDNA was synthesized using Superscript II RNAse H-Reverse Transcriptase (Life Technologies, Karlsruhe, Germany). Four microliters of RNA-elute was added to $0.5 \mu \mathrm{l}$ enzyme (100 units). One microgram of dT15 primer (TIB-Biomol, Berlin, Germany), $1 \mu \mathrm{M}$ random hexamers (Promega, Heidelberg, Germany), $\times 1$ first strand buffer (Life Technologies, Karlsruhe, Germany), $10 \mathrm{~mm}$ DTT (Life Technologies), and $0.5 \mathrm{~mm}$ deoxynucleotide triphosphate (Carl Roth, Karlsruhe, Germany) were combined to form a total reaction volume of $10 \mu \mathrm{l}$. After annealing for 10 minutes at $70^{\circ} \mathrm{C}$, the reaction was allowed to proceed for 50 minutes at $42^{\circ} \mathrm{C}$, followed by 15 minutes at $70^{\circ} \mathrm{C}$ to inactivate the enzyme. After cDNA synthesis, distilled water was added to achieve a final volume of $200 \mu \mathrm{l}$ in each probe.

\section{Real-Time PCR}

TaqMan-PCR was performed with the ABI Prism 7700 Sequence Detection System ${ }^{\mathrm{R}}$ (Perkin Elmer Applied Biosystems, Foster City, California). After target amplification, an oligonucleotide probe containing a fluorescent dye (6-carboxyfluorescein) at its $5^{\prime}$-end and a quencher (6-carboxytetramethylrhodamine) at its $3^{\prime}-$ end annealed to the amplicon and was displaced and cleaved between the reporter and quencher dyes by the nucleolytic activity of the recombinant TaqPolymerase. The amount of product resulting in detectable fluorescence at any given cycle within the exponential phase of PCR was proportional to the initial number of template copies. The number of PCR cycles needed to detect the amplicon was therefore a direct measure of template concentration.

CK- and GAPDH-intron overlapping primers and corresponding oligonucleotide probes were designed by use of the Primer Express software, Version 1.6
(Perkin Elmer Applied Biosystems). The sequences of primers and probes were as follows:

CK7 (Genbank accession no. X13320, amplicon 75 bp): forward primer (exon 4): 5'-TGAATGATGAGATCAACTTCCTCAG-3'; reverse primer (exon 5): 3'-TGTCGGAGATCTGGGACTGC-5'; probe (exon $4+$ exon 5): 5'-FAM-ACCCTCAATGAGACGGAGTTGACAGAGCTG-TAMRA-3'.

CK8 (Genbank accession no. BC000654, amplicon $101 \mathrm{bp}$ ): forward primer (exon 7): 5'-CTGGGATGCAGAACATGAGTATTC-3'; reverse primer (exon 8): 3'-GTAGCTGAGGCCGGCTTGT-5'; probe (exon 7 + exon 8): 5'-FAM-ACCAGCGGCTATGCAGGTGGTCTG-TAMRA-3'.

CK18 (Genbank accession no. BC000180, amplicon $86 \mathrm{bp}$ ): forward primer (exon 5): 5'-GAGACGTACAGTCCAGTCCTTGG-3'; reverse primer (exon 6): 3'CCACCTCCCTCAGGCTGTT-5'; probe (exon $5+$ exon 6): 5'-FAM-CTCCATGAGAAATCTGAAGGCCAGCTTGGTAMRA-3'.

CK19 (Genbank accession no. Y00503, amplicon 103 bp): forward primer (exon 4): 5'-TGAGTGACATGCGAAGCCAATAT-3'; reverse primer (exon 5): 3'-GCGACCTCCCGGTTCAAT-5'; probe (exon 4): 5'-FAMTCATGGCCGAGCAGAACCGGAA-TAMRA-3'.

CK20 (Genbank accession no. X73502, amplicon $105 \mathrm{bp}$ ): forward primer (exon 5): 3'-TCCCAGAGCCTTGAGATAGAACTC-5'; reverse primer (exon 6): 5'GTTGGCTAACTGGCTGCTGTAAC-3'; probe (exon 5 + exon 6): 5'-FAM-CTCCAAAGACTCTTTCATGCTGAGATGGGACT-TAMRA-3'.

GAPDH (Genbank accession no. AF261085, amplicon 226 bp): forward primer (exon 2): 5'-GAAGGTGAAGGTCGGAGTC-3'; reverse primer (exon 3): 3'GAAGATGGTGATGGGATTTC-5'; probe (exon 3): 5'-FAM-CAAGCTTCCCGTTCTCAGCC-TAMRA-3'.

Each PCR assay was repeated three times for each cDNA sample. The $25 \mu \mathrm{l}$ total PCR volume consisted of $5 \mu \mathrm{l} \mathrm{cDNA}, 0.3$ units Taq polymerase (Eurogentec, Seraing, Belgium), $\times 1$ amplification buffer (Eurogentec), $6.5 \mathrm{~mm} \mathrm{MgCl}_{2}, 200 \mu \mathrm{M}$ deoxynucleotide triphosphate, $1.2 \mu \mathrm{m}$ ROX (Perkin Elmer Applied Biosystems), and specific double-labeled probes (Eurogentec) to a final concentration of $100 \mathrm{~nm}$, as well as forward/ reverse primers (MWG-Biotech, Ebersberg, Germany) in the following concentrations: $200 \mathrm{~nm}$ each (CK7), $900 \mathrm{~nm}$ each (CK8), 50/300 nм (CK18), 300/900 nм (CK19), 300 nm each (CK20), and $600 \mathrm{~nm}$ each (GAPDH). After denaturation for 4 minutes at $95^{\circ} \mathrm{C}$, PCR assays were carried out for 40 cycles, with denaturation at $95^{\circ} \mathrm{C}$ for 15 seconds and extension at $65^{\circ} \mathrm{C}$ for 1 minute.

Accurate amplification was achieved through the generation of standard curves by serial dilutions of the different CK- and GAPDH-cDNAs. The RT-PCR results were expressed as the ratio of CK:GAPDH. To monitor amplification of genomic DNA, samples of distilled water and RNA-aliquots without reverse transcription were always amplified as negative controls. Samples with more than $5 \%$ of the RT-PCR signal in the negative control were excluded from further analysis. 


\section{Sensitivity Assay}

Sensitivity of CK RT-PCR was determined by performing serial dilutions of MKN45 gastric cancer cells and HT29 colorectal cancer cells in noncancer control bone marrow samples. The bone marrow sample of one patient was always used to prepare the serial dilutions of the MKN45 and HT29 cell lines. Two sample mixes were prepared at each dilution and CK expression levels were evaluated in three aliquots of this sample by real-time RT-PCR.

\section{References}

Athale UH, Shurtleff SA, Jenkins JJ, Poquette CA, Tan M, Downing JR, and Pappo AS (2001). Use of reverse transcriptase polymerase chain reaction for diagnosis and staging of alveolar rhabdomyosarcoma, Ewing sarcoma family of tumors, and desmoplastic small round cell tumor. J Pediatr Hematol Oncol 23:99-104.

Berezowski K, Stastny JF, and Kornstein MJ (1996). Cytokeratins 7 and 20 and carcinoembryonic antigen in ovarian and colonic carcinoma. Mod Pathol 9:426-429.

Betz C, Papadopoulos T, Buchwald J, Dämmrich J, and Müller-Hermelink HK (1995). Surfactant protein gene expression in metastatic and micrometastatic pulmonary adenocarcinomas and other non-small cell lung carcinomas: Detection by reverse transcriptase-polymerase chain reaction. Cancer Res 55:4283-4286.

Borgen E, Beiske K, Trachsel S, Nesland JM, Kvalheim G, Herstad TK, Schlichting E, Qvist H, and Naume B (1998). Immunocytochemical detection of isolated epithelial cells in bone marrow: Non-specific staining and contribution by plasma cells directly reactive to alkaline phosphatase. J Pathol 185:427-434.

Braun S, Pantel K, Müller P, Janni W, Hepp F, Kentenich CR, Gastroph S, Wischnik A, Dimpfl T, Kindermann G, Riethmüller G, and Schlimok G (2000). Cytokeratin-positive cells in the bone marrow and survival of patients with stage I, II, or III breast cancer. N Engl J Med 342:525-533.

Chelly J, Concordet JP, Kaplan JC, and Kahn A (1989). Illegitimate transcription: Transcription of any gene in any cell type. Proc Natl Acad Sci USA 86:2617-2621.

Chu P, Wu E, and Weiss LM (2000). Cytokeratin 7 and cytokeratin 20 expression in epithelial neoplasms: A survey of 435 cases. Mod Pathol 13:962-972.

Conrad K, Karsten U, Frank KH, and Pasternak G (1988). Immunoblotting of monoclonal anti-cytoskeletal antibodies with cytoskeletal extracts of HeLa and MCF-7 cells. Biomed Biochim Acta 47:697-703.

Datta YH, Adams PT, Drobyski WR, Ethier SP, Terry VH, and Roth MS (1994). Sensitive detection of occult breast cancer by the reverse-transcriptase polymerase chain reaction. J Clin Oncol 12:475-482.

Deguchi T, Doi T, Ehara H, Ito S, Takahashi Y, Nishino $\mathrm{Y}$, Fujihiro S, Kawamura T, Komeda H, and Horie M (1993). Detection of micrometastatic prostate cancer cells in lymph nodes by reverse transcriptase-polymerase chain reaction. Cancer Res 53:5350-5354.

Dingemans AM, Brakenhoff RH, Postmus PE, and Giaccone $G$ (1997). Detection of cytokeratin-19 transcripts by reverse transcriptase-polymerase chain reaction in lung cancer cell lines and blood of lung cancer patients. Lab Invest 77:213220.

Fischmeister G, Zoubek A, Jugovic D, Witt V, Ladenstein R, Fritsch G, Hocker P, Gadner H, and Kovar H (1999). Low incidence of molecular evidence for tumour in PBPC harvests from patients with high risk Ewing tumours. Bone Marrow Transplant 24:405-409.

Ghossein RA, Scher HI, Gerald WL, Kelly WK, Curley T, Amsterdam A, Zhang ZF, and Rosai J (1995). Detection of circulating tumor cells in patients with localized and metastatic prostatic carcinoma: clinical implications. J Clin Oncol 13:1195-1200.

Heiss MM, Allgayer H, Grützner KU, Funke I, Babic R, Jauch KW, and Schildberg FW (1995). Individual development and uPA-receptor expression of disseminated tumour cells in bone marrow: A reference to early systemic disease in solid cancer. Nat Med 1:1035-1039.

Hochhaus A, Weisser A, La Rosee P, Emig M, Müller MC, Saussele S, Reiter A, Kuhn C, Berger U, Hehlmann R, and Cross NC (2000). Detection and quantification of residual disease in chronic myelogenous leukemia. Leukemia 14: 998-1005.

Jung R, Krüger W, Hosch S, Holweg M, Kröger N, Gutensohn K, Wagener C, Neumaier M, and Zander AR (1998). Specificity of reverse transcriptase polymerase chain reaction assays designed for the detection of circulating cancer cells is influenced by cytokines in vivo and in vitro. $\mathrm{Br} \mathrm{J}$ Cancer 78:1194-1198.

Jung R, Petersen K, Krüger W, Wolf M, Wagener C, Zander A, and Neumaier M (1999). Detection of micrometastasis by cytokeratin $20 \mathrm{RT}-\mathrm{PCR}$ is limited due to stable background transcription in granulocytes. Br J Cancer 81:870-873.

Krüger W, Krzizanowski C, Holweg $M$, Stockschlader $M$, Kröger N, Jung R, Mross K, Jonat W, and Zander AR (1996). Reverse transcriptase/polymerase chain reaction detection of cytokeratin-19 mRNA in bone marrow and blood of breast cancer patients. J Cancer Res Clin Oncol 122:679-686.

Lagendijk JH, Mullink H, van Diest PJ, Meijer GA, and Meijer CJLM (1999). Immunohistochemical differentiation between primary adenocarcinomas of the ovary and ovarian metastases of colonic and breast origin. Comparison between a statistical and an intuitive approach. J Clin Pathol 52:283290

Lockett MA, Metcalf JS, Baron PL, O'Brien PH, Elliott BM, Robison JG, and Cole DJ (1998). Efficacy of reverse transcriptase-polymerase chain reaction screening for micrometastic disease in axillary lymph nodes of breast cancer patients. Am Surg 64:539-544.

Loy TS and Calaluce RD (1994). Utility of cytokeratin immunostaining in separating pulmonary adenocarcinomas from colonic adenocarcinomas. Am J Clin Pathol 102:764-767.

Loy TS, Calaluce RD, and Keeney GL (1996). Cytokeratin immunostaining in differentiating primary ovarian carcinoma from metastatic colonic adenocarcinoma. Mod Pathol 9:1040-1044.

McIntyre IG, Spreckley K, Clarke RB, Anderson E, Clarke NW, and George NJ (2000). Optimization of the reverse transcriptase polymerase chain reaction for the detection of circulating prostate cells. Br J Cancer 83:992-997. 
Moll R (1993). Cytokeratins as markers of differentiation. Expression profiles in epithelia and epithelial tumors. Veröff Pathol 142:1-197.

Moll R, Franke WW, Schiller DL, Geiger B, and Krepler R (1982). The catalog of human cytokeratins: Patterns of expression in normal epithelia, tumors and cultured cells. Cell 31:11-24.

Moll R, Zimbelmann R, Goldschmidt MD, Keith M, Laufer J, Kasper M, Koch PJ, and Franke WW (1993). The human gene encoding cytokeratin 20 and its expression during fetal development and in gastrointestinal carcinomas. Differentiation 53:75-93.

Moscinski LC, Trudeau WL, Fields KK, and Elfenbein GJ (1996). High-sensitivity detection of minimal residual breast carcinoma using the polymerase chain reaction and primers for cytokeratin 19. Diagn Mol Pathol 5:173-180.

Naito Y, Kino I, Horiuchi K, and Fujimoto D (1984). Promotion of collagen production by human fibroblasts with gastric cancer cells in vitro. Virchows Arch B Cell Pathol Incl Mol Pathol 46:145-154.

Noguchi S, Aihara T, Nakamori S, Motomura K, Inaji H, Imaoka S, and Koyama H (1994). The detection of breast carcinoma micrometastases in axillary lymph nodes by means of reverse transcriptase-polymerase chain reaction. Cancer 74:1595-1600.

Pantel K, Izbicki J, Passlick B, Angstwurm M, Haussinger K, Thetter O, and Riethmüller G (1996). Frequency and prognostic significance of isolated tumour cells in bone marrow of patients with non-small-cell lung cancer without overt metastases. Lancet 347:649-653.

Ruud P, Fodstad O, and Hovig E (1999). Identification of a novel cytokeratin 19 pseudogene that may interfere with reverse transcriptase-polymerase chain reaction assays used to detect micrometastatic tumor cells. Int $\mathrm{J}$ Cancer 80:119-125.

Salbe C, de Cremoux P, Bonneton C, Manet S, Almeida A, Magdelenat H, Bourstyn E, and Robine S (2000). Illegitimate villin transcripts in normal bone marrow precludes detection of colon cancer micrometastases. Int J Biol Markers 15:4143.

Savtchenko ES, Schiff TA, Jiang CK, Freedberg IM, and Blumenberg $M$ (1988). Embryonic expression of the human 40-kD keratin: Evidence from a processed pseudogene sequence. Am J Hum Genet 43:630-637.

Slade MJ, Smith BM, Sinnett HD, Cross NC, and Coombes RC (1999). Quantitative polymerase chain reaction for the detection of micrometastases in patients with breast cancer. J Clin Oncol 17:870-879.
Smith BM, Slade MJ, English J, Graham H, Luchtenborg M, Sinnett HD, Cross NC, and Coombes RC (2000). Response of circulating tumor cells to systemic therapy in patients with metastatic breast cancer: Comparison of quantitative polymerase chain reaction and immunocytochemical techniques. $\mathrm{J}$ Clin Oncol 18:1432-1439.

Smith MR, Biggar S, and Hussain M (1995). Prostate-specific antigen messenger RNA is expressed in non-prostate cells: implications for detection of micrometastases. Cancer Res 55:2640-2644.

Stigbrand T, Andres C, Bellanger L, Bishr Omary M, Bodenmuller $\mathrm{H}$, Bonfrer $\mathrm{H}$, Brundell J, Einarsson $\mathrm{R}$, Erlandsson $\mathrm{A}$, Johansson A, Leca JF, Levi M, Meier T, Nap M, Nustad K, Seguin P, Sjodin A, Sundstrom B, van Dalen A, Wiebelhaus E, Wiklund B, Arlestig L, and Hilgers J (1998). Epitope specificity of 30 monoclonal antibodies against cytokeratin antigens: The ISOBM TD5-1 Workshop. Tumour Biol 19:132-152.

Traweek ST, Liu J, and Battifora H (1993). Keratin gene expression in non-epithelial tissues. Detection with polymerase chain reaction. Am J Pathol 142:1111-1118.

Tse WT and Forget BG (1990). Reverse transcription and direct amplification of cellular RNA transcripts by Taq polymerase. Gene 88:293-296.

van Dongen JJ, Macintyre EA, Gabert JA, Delabesse E, Rossi V, Saglio G, Gottardi E, Rambaldi A, Dotti G, Griesinger F, Parreira A, Gameiro P, Diaz MG, Malec M, Langerak AW, San Miguel JF, and Biondi A (1999). Standardized RT-PCR analysis of fusion gene transcripts from chromosome aberrations in acute leukemia for detection of minimal residual disease. Report of the BIOMED-1 Concerted Action: Investigation of minimal residual disease in acute leukemia. Leukemia 13: 1901-1928.

Van Trappen PO, Gyselman VG, Lowe DG, Ryan A, Oram DH, Bosze P, Weekes AR, Shepherd JH, Dorudi S, Bustin SA, and Jacobs IJ (2001). Molecular quantification and mapping of lymph-node micrometastases in cervical cancer. Lancet 357: 15-20.

Vollmers HP, Stulle K, Dämmrich J, Pfaff M, Papadopoulos T, Betz C, Saal K, and Müller-Hermelink HK (1993). Characterization of four new gastric cancer cell lines. Virchows Arch B Cell Pathol Incl Mol Pathol 63:335-343.

Yang Y, Hao J, Liu X, Dalkin B, and Nagle RB (1997). Differential expression of cytokeratin mRNA and protein in normal prostate, prostatic intraepithelial neoplasia, and invasive carcinoma. Am J Pathol 150:693-704. 